\title{
OS LIMITES DA DEMOCRACIA REPRESENTATIVA: ATOMIZAÇÃO, PASSIVIDADE E AFASTAMENTO DA POLÍTICA
}

\author{
Tamíris Moreira Simão 1 \\ Universidade Federal de Minas Gerais (UFMG) \\ https://orcid.org/0000-0002-6427-5025 \\ E-mail: tamiris.msimao@gmail.com
}

\section{RESUMO:}

Ellen Wood, em Democracia contra o capitalismo, defende duas importantes teses: o capitalismo inaugura um novo tipo de exploração e de extorsão da classe trabalhadora que não depende diretamente da extorsão do Estado; com isso, torna-se possível que alguns direitos políticos sejam estendidos a um número maior de pessoas, com a instituição da "democracia representativa". Por outro lado, a participação política dos trabalhadores é limitada: ao identificar a democracia com a representação política, as classes dominantes criaram uma ilusão de participação política popular que é, na verdade, extremamente limitada, ou quase nula. Neste artigo, pretendemos mostrar alguns dos principais limites da democracia representativa, e como essa democracia atomiza os cidadãos e os mantém afastados de uma participação política efetiva. Para isso, recorreremos a outros teóricos influentes como Jean-Jacques Rousseau, Bernard Manin, Hanna Pitkin, Noam Chomsky.

PALAVRAS-CHAVE: Democracia; Representação Política; Capitalismo.

\section{THE LIMITS OF THE REPRESENTATIVE DEMOCRACY: ATOMIZATION, PASSIVITY AND DISTANCING FROM POLITICS}

\begin{abstract}
:
In Democracy against capitalism, Ellen Wood defends two important theses: capitalism inaugurates a new kind of exploitation and extortion of the working class that is not directly dependent on state extortion; this makes it possible for some political rights to be extended to a larger number of people through the establishment of "representative democracy". On the other hand, workers' political participation is limited: by identifying democracy with political representation, the ruling classes have created an illusion of popular political participation that is, in fact, extremely limited, or almost nil. In this article, we intend to show some of the main limits of representative democracy, and how this "democracy" atomizes citizens and keeps them away from effective political participation. For this, we will use other influential theorists such as Jean-Jacques Rousseau, Bernard Manin, Hanna Pitkin, Noam Chomsky.
\end{abstract}

KEYWORDS: Democracy; Political Representation; Capitalism.

\footnotetext{
${ }^{1}$ Doutorando(a) em Filosofia na Universidade Federal de Minas Gerais (UFMG), Belo Horizonte - MG, Brasil.
} 


\section{Introdução}

Na contemporaneidade, tornou-se usual tratar o sistema representativo como uma espécie de sinônimo de democracia; no entanto, veremos aqui que democracia e representação não apenas são coisas distintas, como o sistema representativo distanciou os cidadãos da participação popular efetiva, esvaziando o sentido da palavra democracia.

Iremos expor, na primeira parte deste texto, alguns elementos que diferenciam a democracia - conforme compreendida em seu sentido original - da representação. Buscaremos também caracterizar a representação, tendo como base autores como Hannah Pitkin e Bernard Manin, além de mostrar como a representação se relaciona com a mídia e com o poder de quem controla os meios de comunicação, considerando principalmente Noam Chomsky. Na última parte de nosso trabalho, apresentaremos, a partir da obra "Democracia contra o capitalismo" de Ellen Wood, de que forma ocorreu a identificação entre democracia e representação e de que modo o sentido de democracia foi esvaziado a partir disso.

\section{A representação política}

No final do século XVIII, a representação e a democracia não apenas não se confundiam, como a representação era compreendida como um sistema superior de organização política. Para exemplificarmos essa defesa feita a favor da representação, recorremos aos federalistas ${ }^{2}$ e ao Abade de Sieyès.

Alexander Hamilton, no Federalist 35, argumenta que a representação política é superior à democracia direta pois elege pessoas mais capacitadas para os cargos de poder. De acordo com o federalista, os comerciantes, os proprietários rurais as pessoas das "learned professions" são os representantes naturais de todas as outras profissões, pois detêm conhecimentos superiores e estariam mais habilitados para representarem o povo [Cf. HAMMILTON, 2003, p. 159]. Para os federalistas, o maior ponto contra a democracia não é a impossibilidade de reunir todos os cidadãos em assembleia, mas sim a compreensão de que o pequeno número de pessoas eleitas para representarem o povo é dotado de uma sabedoria superior e, por isso, detêm maior capacidade para tomar decisões políticas do que uma assembleia constituída por todos os cidadãos. Essa pequena parcela eleita é, para eles, quem conhece, de fato, os verdadeiros interesses do país e, portanto, seria capaz de tomar decisões considerando o melhor para a nação de maneira imparcial. Já o Abade de Sieyès compreende que a superioridade da representação consiste no fato de que as pessoas, nas sociedades comerciais, despendem maior tempo em atividades produtivas e, por isso, a tarefa política deve ser compreendida e organizada a partir da divisão social do trabalho. Ou seja, os representantes devem ser pessoas especializadas nas questões políticas e isso deixaria as demais livres para atuarem nos trabalhos de produção e de comércio [SYEYÈS, 2003, p. 48].

É interessante notar que antes das revoluções Francesa e Americana, mais especificamente em $1762^{3}$, o filósofo genebrino Jean-Jacques Rousseau já havia criticado essa justificativa apresentada por Sieyès. Para Rousseau, quando a população considera que é mais importante ocupar-se com atividades produtivas e comerciais do que com a atividade política, o corpo político se encontra próximo de seu colapso. No Livro III, Capítulo XV, do Contrato Social, o filósofo nos diz: "Desde que o serviço público deixa de constituir a atividade principal dos cidadãos e eles preferem servir com sua bolsa a servir com sua pessoa, o Estado já se encontra próximo da ruína" [ROUSSEAU, 1987, p. 106]. Enquanto os federalistas e outros defensores do sistema representativo chamavam essa instituição do sistema representativo de "república",

\footnotetext{
2 Mais especificamente ao "The Federalist Papers" escritos por James Madison, Alexander Hamilton e John Jay

3 Ano da primeira publicação de Du contrat social.
} 
Rousseau considerava que o fato de atribuir representantes constituía em uma corrupção da verdadeira república.

No sistema representativo, a grande maioria dos cidadãos está excluída da participação ativa na política. Uma minoria é eleita para deliberar e criar leis, bem como para executá-las, enquanto o povo meramente assiste às tomadas de decisão, sem mecanismos institucionais de intervenção direta na política. $O$ grande problema da representação para Rousseau, inclusive, é o fato de os representantes terem total autonomia para agir. Ainda no capítulo XV, o filósofo assevera:

Os deputados do povo não são, nem podem ser seus representantes; não passam de comissários seus, nada podendo concluir definitivamente. É nula toda lei que o povo diretamente não ratificar; em absoluto não é lei. O povo inglês pensa ser livre e muito se engana, pois só o é durante a eleição dos membros do parlamento; uma vez estes eleitos, ele é escravo, não é nada [ROUSSEAU, 1987, p. 108].

Ao dizer que os deputados "não podem ser seus representantes", Rousseau entende que a palavra "representante" implica em autonomia 4. Isso fica claro quando à palavra "representante" ele contrapõe "comissários" - estes sim admitidos como legítimos para o autor. A diferença entre "representante" e "comissário" consiste no fato de que o segundo discutirá em assembleia, mas todas as leis devem ser diretamente ratificadas pelo povo para que possam ser promulgadas.

É relevante também explicarmos que, para Rousseau, a ratificação direta pelo povo em todas as leis não é uma democracia, mas sim um requisito básico para a república, tal como apresentada no Contrato social. Isso fica nítido ao entendermos a divisão feita pelo filósofo entre poder executivo e poder legislativo [Cf. ROUSSEAU, 1987, P. 73]. O poder executivo é o governo ou administração, que pode apresentar qualquer formato (monarquia - no sentido de "governo de um", mas que não pode ser confundida de maneira nenhuma com a monarquia do antigo regime -, aristocracia ou democracia), e está submetido ao poder legislativo.

Já o poder legislativo, chamado pelo autor de poder Soberano, deve necessariamente ser formado por todos os cidadãos. Isso significa que caso todos os cidadãos não possam participar ativamente das assembleias devido ao tamanho dos Estados modernos, eles devem, ao menos, ratificar diretamente todas as leis pelo voto.

Rousseau só considera que há democracia quando o poder executivo está nas mãos do povo; o fato de que todos participem do poder legislativo (Soberano) é um fundamento básico para que o Estado seja considerado uma república, ou seja, não se confunde com a democracia, que se configura com o povo sendo o portador do poder executivo. Ou seja, para Rousseau, uma constituição que adota o sistema representativo não seria considerado como uma boa república e jamais seria concebida como democracia. Como vimos na citação do livro III, capítulo XV, o filósofo ironiza os ingleses que se consideravam livres por elegerem os membros do parlamento, mas eram, na verdade, escravos, pois sua única liberdade consistia em eleger representantes. Fora do período das eleições, os cidadãos não possuem nenhum mecanismo institucional para participarem ativamente da política nesse tipo de sistema. Nossa participação se restringe às eleições de representantes - que, a partir do momento em que são eleitos, tornam-se autônomos ${ }^{5}$, pois não precisam de nenhum respaldo popular -, e não só consideramos que vivemos em uma república, como acreditamos que estamos em uma democracia. Como veremos a seguir, essa questão da autonomia, criticada por Rousseau, também é discutido por autores contemporâneos.

\footnotetext{
${ }^{4}$ Rousseau foi um leitor de Hobbes, a quem o filósofo genebrino se opõe em diversos momentos ao longo do Contrato social e em outras de suas obras. Provavelmente a noção de representação que ele adota é aquela cunhada pelo filósofo inglês. Para uma maior compreensão da discussão, conferir especialmente os capítulos XVI, XVII e XVIII de Leviathan.

${ }^{5}$ A respeito da autonomia ou "independência" dos representantes, conferir MANIN, 1997, p. 163 e URBINATI, 2006, p. 45.
} 
Hanna Pitkin, em The concept of representation, mostra que a representação não é simples de ser definida, mas, pela leitura da obra, notamos que a autonomia é um ponto importante para o funcionamento do sistema. Nesse livro, a autora comenta sobre alguns modelos a partir dos quais a representação pode ser concebida, sendo as duas principais formas, segundo o nosso entendimento, a representação por autorização e a representação descritiva.

A representação por autorização ${ }^{6}$, conforme explica Hanna Pitkin, é a concepção de que o representante eleito é autorizado a agir. Desse modo, o representante recebe um direito de agir que ele não possuía antes e o representado é responsável pelas consequências das decisões do representante, uma vez que foi ele quem concedeu essa autorização. Segundo Hanna Pitkin, esse modo de compreender a representação concorre fortemente em favor do representante, isso porque seus direitos são alargados e suas responsabilidades diminuídas. Os representados, por outro lado, têm seus direitos estreitados e suas responsabilidades aumentadas [Cf. PITKIN, 1967, p. 19]. A autora compreende a autorização desse modo, pois enquanto os representantes possuem o direito de agir e de tomar decisões politicamente, a responsabilidade das consequências de suas decisões recai sobre os representados que o autorizaram a agir, mas que não possuem, eles próprios, direito às deliberações e ações políticas institucionais ${ }^{7}$.

Além disso, as possibilidades que os representados possuem de exigir como devem ser tomadas as decisões pelos representantes são limitadas, ou mesmo institucionalmente nulas:

Representação é uma espécie de "caixa preta" formada pela atribuição de autoridade, na qual o representante faz o que quer que ele deseje. Se ele deixar a caixa, ele ultrapassa os limites, ele deixa de representar. Não existe boa ou má representação, ou ele representa ou não representa. Não existe uma atividade de representar ou os deveres do representante; qualquer coisa feita depois do ato da autorização e dentro de seus limites é, por definição, representação [PITKIN, 1967, p. 39].

Ou seja, a partir do momento em que o representante é eleito, ou autorizado a agir e a deliberar, cessa qualquer comprometimento com suas promessas de eleição. Ele possui o direito de agir conforme desejar, não cabendo nenhuma ferramenta institucional que permita aos representados exigir que as decisões ocorram de outra maneira. A esse respeito, Bernard Manin, em The Principles of Representative Government, salienta que, no sistema representativo, os representantes apenas mantêm suas promessas por ser essa a melhor forma de garantir a reeleição, possuindo, no entanto, plena autonomia para não as cumprir:

\footnotetext{
Sem dúvidas, os representantes possuem um incentivo para manter suas promessas. Manter promessas é uma norma social fortemente enraizada, e quebrá-las torna-se um estigma que implicará em dificuldades para a reeleição. Representantes permanecem, no entanto, livres para sacrificar sua perspectiva de reeleição se, em circunstâncias excepcionais, outras considerações parecem mais importantes do que sua própria carreira [MANIN, 1997, p 167].
}

Ou seja, a principal tarefa dos representados no sistema representativo é designar representantes, ou, de acordo com a concepção de representação por autorização, o papel do povo é o de autorizar os representantes a agirem em seu nome. Hanna Pitkin chama a autorização de concepção formalista, pois esta é a abordagem da representação sob a perspectiva

\footnotetext{
6 Trata-se da concepção de representação cunhada por Thomas Hobbes, a respeito da qual nos referimos na nota de rodapé anterior.

7 Ainda que as Constituições que adotam a democracia representativa possuam a possibilidade de referendos e plebiscitos, eles são utilizados apenas em casos pontuais. As leis são, em geral, decididas pelo Congresso ou Parlamento, sem nenhuma consulta popular direta. Nos Estados Unidos existe também, desde 1911, a possiblidade de recall, que é inutilizado. Já o mandato imperativo foi extinto das democracias modernas, restando-nos apenas o modelo de representação, no qual os representantes possuem autonomia para deliberarem.
} 
formal, que se baseia no ato pelo qual o representado autoriza o representante a agir, sendo definida, portanto, antes mesmo do início do trabalho do representante.

A segunda noção de representação que apresentaremos aqui é a descritiva. Essa concepção compreende que a representação acontece por uma correspondência ou conexão entre o representante e o representado. O representante é como um espelho que reflete o representado. Hanna Pitkin pontua que diferente da representação como autorização, na representação descritiva o representante não age no lugar dos representados, mas em prol deles.

A autora explica que os principais defensores da representação descritiva são aqueles que defendem a representação proporcional - uma forma de representação que comporte as diversidades presentes entre os eleitores -; e, de acordo com eles, o congresso deve refletir a sociedade em seus diferentes aspectos, deve ser uma imagem dos diversos representados.

Essa concepção de representação é, talvez, a principal fonte de confusão entre as pessoas que não compreendem que em qualquer tipo de representação há sempre autonomia por parte dos representantes. Mesmo sob uma perspectiva descritiva, na qual o representante deveria fazer aquilo que o representado deseja, agindo em prol dele, o representante continua a ser livre de qualquer obrigação institucional para com os representados. Ou seja, o representado não possui nenhum poder institucional para exigir que o representante cumpra com aquilo a que se comprometeu.

A representação política, portanto, cria uma ideia de ampla participação popular por meio do sufrágio universal, mas a participação se resume à escolha de representantes que agirão autonomamente, enquanto os representados ficam impedidos de agir politicamente dentro das esferas de poder institucional. Ou seja, a representação política não tem propriamente um caráter democrático: embora ela adote um sistema inclusivo com o direito ao sufrágio universal, os postos de poder não são acessíveis a todos. Os representantes para serem eleitos ainda dependem do auxílio das elites e, portanto, agirão de acordo com os interesses das elites, o que se desvincula do significado da palavra democracia - governo do povo.

Bernard Manin trata das distinções entre democracia e governo representativo - que, para ele, são sistemas diferentes - e um ponto interessante levantado pelo autor é que a principal diferença entre a democracia ateniense e a democracia representativa moderna, de acordo com seu entendimento, reside no uso do sorteio. Enquanto a democracia ateniense utilizava o sorteio para a seleção dos delegados políticos, a representação utiliza majoritariamente a eleição - em alguns casos combinada com hereditariedade, como em monarquias parlamentares - para a escolha de seus atores políticos, considerando o sorteio um modo absurdo e rudimentar. Segundo o autor, no entanto, a escolha por sorteios é o principal mecanismo que faz do regime na antiga Atenas uma verdadeira democracia. Isso porque, em tal sistema de seleção, absolutamente todos os cidadãos possuem as mesmas chances de ocuparem os cargos políticos.

A representação, por outro lado, sendo fortemente associada ao sistema eletivo, constituise, de acordo com o autor, num sistema aristocrático que sempre elege uma elite para os cargos de poder. Mais do que isso, as eleições não apenas criam elites políticas, como o modo como ela funciona permite que apenas as elites alcancem os principais postos. A respeito disso, Manin enfatiza que, atualmente, aqueles que conseguem ser eleitos são os que de alguma forma têm a seu favor os meios de comunicação. A elite contemporânea, portanto, é uma elite formada a partir das mídias de massa.

Bernard Manin explica ainda que durante certo tempo os cidadãos escolhiam seus votos em consonância com os partidos com os quais se identificavam. Os partidos, até então, apresentavam-se de acordo com seus programas políticos.

Hoje, no entanto, a estratégia eleitoral reside na construção de um modelo que tem como objetivo formatar uma imagem de liderança, imagem essa que é construída e vendida como um produto. Não é à toa que as campanhas presidenciais investem tanto dinheiro em marketing: em 
uma democracia de espectadores - termo cunhado por Noam Chomsky para designar a democracia representativa -, a imagem produzida é essencial para o alcance da vitória eleitoral.

\section{Mídia e atomização}

Em Mídia, Noam Chomsky explora a importância da imprensa e das mídias de massa para a formatação da opinião pública e a "criação do consenso" naquilo que ele chama de "democracia de espectadores" [CHOMSKY, 2014, p. 7]. O autor explica que, de acordo com seguidores de John Dewey e com o pensador liberal Walter Lippman, a construção do consenso era tarefa necessária e deveria ser guiada por intelectuais que, de acordo com eles, saberiam melhor quais eram os caminhos que o país deveria tomar. Ou seja, essa tese segue a mesma compreensão dos federalistas a respeito da justificativa para a escolha da representação política como o melhor sistema para a república: existe sempre uma elite que sabe deliberar politicamente, enquanto o restante da população apenas assiste às tomadas de decisão.

No caso da discussão feita por Chomsky, o cenário é ainda mais grave: a mídia é utilizada para convencer a população de posições contrárias às quais ela inicialmente defendia. Dois importantes exemplos utilizados pelo autor são a Primeira Guerra Mundial e a Guerra do Vietnã - em ambos conflitos bélicos, o povo dos Estados Unidos era majoritariamente pacifista e se opunha às guerras, mas foram convencidos do contrário.

Na Primeira Guerra, o então presidente dos Estados Unidos, Woodrow Wilson, formou uma comissão de propaganda governamental para reverter a opinião pública, chamada Comissão Creel. A equipe foi tão eficaz que transformou, em seis meses, um povo que era então pacifista em uma população "histérica e belicosa" [CHOMSKY, 2014, p. 7]. Também nesse período as mesmas técnicas foram utilizadas para gerar o "Pânico Vermelho", que resultou em perseguição contra comunistas, anarquistas e contra a liberdade de imprensa. Esse controle de formatação da opinião pública tanto a favor da Guerra, quanto contra o "perigo comunista", é engendrado a partir de mentiras e de instrumentos de manipulação de massa:

\footnotetext{
Eles lançaram mão dos instrumentos mais diversos. Inventaram, por exemplo, que os hunos cometiam uma série de atrocidades, como arrancar os braços de bebês belgas, e toda sorte de fatos horripilantes que ainda podem s encontrados em alguns livros de história. Boa parte desse material foi criada pelo Ministério da Propaganda britânico, dedicado à época - como consta de suas resoluções secretas - "a controlar a opinião da maior parte do mundo". Acima de tudo, porém, eles queriam controlar a opinião dos membros mais inteligentes da comunidade norte-americana, os quais, então, difundiriam a propaganda política que estavam forjando e levariam o país pacifista à histeria belicista. Funcionou. E funcionou muito bem. E nos deixou uma lição: a propaganda política patrocinada pelo Estado, quando apoiada pelas classes instruídas e quando não existe espaço para contestá-la, pode ter consequências importantes. Foi uma lição aprendida por Hitler e por muitos outros e que tem sido adotada até os dias de hoje [CHOMSKY, 2014, p. 7].
}

Outro exemplo interessante utilizado por Chomsky sobre o papel das propagandas de massa ocorreu anos mais tarde, também nos Estados Unidos. Na década de 1930, os trabalhadores começaram a aperfeiçoar sua capacidade de organização; em 1935, a Lei Wagner, que instituía o direito de organização, foi implementada. Isso significou um problema para o sistema: aqueles que deveriam ser "espectadores" na democracia representativa estavam agindo politicamente e conquistando ganhos no plano legislativo. A ameaça era, portanto, iminente: se essas pessoas continuassem a se organizar, poderiam conseguir alcançar postos de poder e protagonizarem os espaços políticos.

Para que a representação funcione da melhor maneira possível, é preciso que as pessoas permaneçam atomizadas, sem nenhum tipo de organização de classe; e foi isso que o aparato 
ideológico da burguesia buscou fazer: de acordo com Chomsky, os empresários conseguiram se unir para colocar a população contra os grevistas, "apresentando-os como desordeiros, nocivos à população e contrários ao interesse geral" [CHOMSKY, 2014, p. 12]. Com isso, os trabalhadores voltaram a se atomizar, readquirindo a "passividade" tão cara ao sistema representativo.

Sartre também nota essa passividade e atomização dos indivíduos no sistema representativo. $O$ pesquisador Silvio Luiz de Almeida, ao falar sobre um texto feito pelo filósofo francês para prefácio do livro Les Maos en France, explica-nos que:

\begin{abstract}
A serialização e a atomização impostas ao trabalhador impedem a formação do grupo capaz de uma ação concreta e, portanto, unificadora [...]. Desse modo, diante de práticas atomizadoras, caracterizadas pela opressão e pela divisão, o pensamento serial é reproduzido pelo trabalhador como se fosse o seu próprio quando, na verdade, é o pensamento da classe dominante [ALMEIDA, 2016, p. 182].
\end{abstract}

Também encontramos o tema das eleições e da atomização em outro texto sartreano, um artigo chamado Eléctions, piège à cons, publicado em Le temps modernes. Nele, Sartre assevera que as eleições são uma forma de atomizar ou serializar os homens. As urnas em si já mostram essa atomização: cada um vota de forma individual e isolada, em cabines, e com a garantia do voto secreto. Essa ação individual e isolada é o único meio institucional de participação política no sistema representativo.

As eleições não apenas são a única forma institucional efetiva de participar da política, como a participação nas eleições se limita ao voto feito isoladamente. Os cidadãos atomizados não possuem nenhuma possibilidade de interferirem nos rumos das eleições. Para explicar isso, Sartre utiliza o seguinte exemplo: um homem votou em um candidato do Partido Comunista em determinada eleição, e esse candidato não foi eleito. Nas eleições seguintes, quatro anos depois, ele não poderá fazer nada para que esse candidato ganhe: a vitória do Partido Comunista não depende dele, a única ação que ele pode tomar é votar novamente no candidato; mas para que a vitória aconteça é necessário que pessoas que votaram em outros partidos mudem seus votos nas próximas eleições e decidam votar no Partido Comunista. $O$ cidadão que tem no voto sua única possibilidade de ação política não possui nenhum poder de decidir as eleições; o que modificará os outros votos são os instrumentos de propaganda e o uso das mídias de massa.

Para Sartre, a democracia representativa é uma mistificação. Em tese, as Câmaras e Senados são o que melhor representam a "opinião pública", mas não há opinião pública em uma sociedade atomizada e serializada. Há somente a opinião das classes dominantes, que é incutida na classe trabalhadora como se essa fosse sua própria opinião; e, considerando que essa classe se encontra atomizada e sem possibilidades de participação política direta, é muito fácil manter essa estrutura de poder. Ora, a democracia burguesa, além de não nos parecer uma democracia de fato, apresenta também limites ao que deveria ser o governo do demos. A única forma de participação - as eleições - é totalmente passiva e serializada, perpetuando um modo de dominação mascarado.

\title{
A participação passiva na democracia burguesa
}

Outra autora que escreve a respeito da passividade contida na democracia representativa e sobre os limites da democracia burguesa é Ellen Wood. Mas, para explicar esses pontos, a autora retoma a própria formação desse tipo de democracia.

No livro Democracia contra capitalismo, Ellen Wood explica que nas sociedades précapitalistas, a mais-valia era extraída do trabalhador mediante algum tipo de poder político; a extração dependia de modos extraeconômicos, ou seja, por meio da coação política, legal ou militar; ou ainda pelas "obrigações ou deveres tradicionais" como, por exemplo, por meio de 
impostos ${ }^{8}$. Já no capitalismo a apropriação da mais-valia é, em certa medida, separada dessa esfera pública, o que engendra uma "privatização do poder", conforme explica Ellen Wood:

A diferenciação da esfera econômica no capitalismo pode, portanto, ser assim resumida: as funções sociais de produção e distribuição, extração e apropriação de excedentes, e a alocação do trabalho social são, de certa forma, privatizadas e obtidas por meios não autoritários e não políticos. [...] Os poderes de apropriação de mais-valia e de exploração não se baseiam diretamente nas relações de dependência jurídica ou política, mas sim numa relação contratual entre produtores "livres" - juridicamente livres e livres dos meios de produção - e um apropriador que tem a propriedade privada absoluta dos meios de produção [WOOD, 2003, p. 35].

A mais-valia passa a ser extraída do trabalhador no próprio processo produtivo. Não é mais necessária uma coação direta para extorquir o trabalhador: isso passa a acontecer no próprio trabalho, à medida que é fixado um salário que não corresponde à produção real do trabalhador. Isso não significa, no entanto, que a política seja de fato apartada da economia na sociedade capitalista. Afinal, no capitalismo é necessário o aparato do Estado que manterá a estrutura de dominação. O Estado é essencial para garantir "a propriedade privada absoluta, a relação contratual que prende o produtor ao apropriador, o processo de troca de mercadorias" [WOOD, 2003, p. 35] e formas institucionais de coação e polícia. Desse modo, ainda que o poder político esteja formalmente separado do poder econômico, o primeiro está a serviço do segundo. Como nos diz Ellen Wood:

Portanto, se quisermos entender o desenvolvimento sem precedentes do capitalismo, teremos de entender como as relações de propriedade e de classe, bem como as funções de apropriação e de distribuição de excedentes, separam-se - apesar de continuarem a se servir delas - das instituições coercitivas que constituem o Estado, e continuam a se desenvolver autonomamente [WOOD, 2003, p. 38].

É por causa dessa separação entre os poderes que o capitalismo é capaz de permitir uma democratização de direitos políticos e civis sem modificar as relações de poder e de opressão. As sociedades pré-capitalistas precisavam do poder institucional político para extorquir os mais pobres e manter a divisão e os privilégios de classes. No capitalismo, a própria forma produtiva explora os mais pobres e mantém o poder e os privilégios das classes mais altas. Ainda assim, Ellen Wood ressalva:

\footnotetext{
Mas nunca foi óbvio que o capitalismo poderia sobreviver à democracia, pelo menos nesse sentido "formal". À medida que o crescimento das relações de propriedade capitalistas começou a separar propriedade de privilégio, principalmente onde o trabalho livre ainda não estava sujeito às novas disciplinas do capitalismo industrial e à falta absoluta de propriedade, as classes dominantes da Europa passaram a se preocupar muito com os perigos oferecidos pela multidão trabalhadora. Durante muito tempo, parecia que a única solução seria a preservação de algum tipo de divisão entre governantes e produtores, entre uma elite proprietária e politicamente privilegiada e uma multidão trabalhadora destituída de direitos. Desnecessário dizer, os direitos políticos também não foram distribuídos generosamente quando por fim se garantiu às classes trabalhadoras o acesso a eles, depois de longas lutas populares que enfrentaram fortes resistências [WOOD, 2003, p. 174].
}

Ainda que a manutenção do poder e o capitalismo pudessem sobreviver a um alargamento dos direitos políticos e civis, isso não era óbvio e, portanto, foram necessárias lutas

\footnotetext{
${ }^{8}$ Para ver mais sobre o desenvolvimento dos modos de extorsão pré-capitalista, recomendamos a leitura dos dois primeiros capítulos da Primeira Parte do livro Linhagens do Estado Absolutista de Perry Anderson.
} 
políticas para que os trabalhadores conseguissem conquistar esses direitos. Mesmo que o sistema capitalista permita a manutenção de um poder privado, pautado na forma de produção que explora, por si, os trabalhadores, as elites nunca deixaram de temer as consequências de uma classe trabalhadora detentora de direitos políticos. É a partir desse cenário que Ellen Wood explica a ascensão de uma nova concepção de democracia.

A autora assevera que, depois da revolução americana, os ideais democráticos já estavam fortes demais para serem rechaçados. Como vimos na primeira seção, os federalistas entendiam que a representação não era o mesmo que a verdadeira democracia e defendiam o sistema representativo como superior. Mas seus argumentos a favor da representação não foram suficientes para acalmar os defensores dos ideais democráticos, já consolidados e, desse modo, foi necessário operar essa identificação entre democracia e representação. Os "Pais Fundadores", portanto, em vez de persistirem na recusa contra a democracia, esvaziaram todo o sentido da palavra "cidadania", criando instituições que limitariam o poder dos cidadãos na vida política. Os direitos políticos são, portanto, alargados em nome dos ideais democráticos, mas já não existe uma cidadania ativa tal como na democracia ateniense; a participação do povo dentro da esfera política passa a restringir-se a um modo passivo de participação. Os federalistas, portanto, propõem uma forma de aristocracia "disfarçada" de democracia:

O ideal federalista pode ter sido a criação de uma aristocracia que combinasse riqueza e virtude republicana [...]; mas a tarefa prática era manter uma oligarquia proprietária com o apoio eleitoral da multidão popular. Isso também exigiu dos federalistas uma ideologia, e, especificamente, uma redefinição de democracia, que disfarçasse as ambiguidades de seu projeto oligárquico. Foram os antidemocratas vitoriosos nos Estados Unidos que ofereceram ao mundo moderno a sua definição de democracia, uma definição em que a diluição do poder popular é ingrediente essencial. Se as instituições políticas americanas não chegaram a ser imitadas por toda parte, a experiência americana deixou um legado universal [WOOD, 2003, p. 185].

Essa nova concepção de democracia é, como podemos notar, a democracia representativa. Ora, a representação já existia na política antes da fundação dos Estados Unidos e antes mesmo do desenvolvimento do Capitalismo. A novidade foi a identificação do sistema representativo com a democracia. A participação na escolha dos representantes por meio do sufrágio e a extensão da cidadania foram suficientes para que esse sistema fosse considerado como democrático. A democracia representativa é, portanto, segundo Ellen Wood, uma inovação americana.

É interessante notarmos que os federalistas não apenas limitam a participação dos cidadãos à escolha dos representantes, como consideram que os comerciantes eram os representantes de todos os trabalhadores. Vimos na primeira seção que Hamilton defende que a democracia moderna é superior à democracia antiga justamente por selecionar os "mais capacitados" para os cargos de poder, e essa concepção é amplamente difundida entre os federalistas, que concebem os trabalhadores como incapazes de participarem das deliberações políticas, restringindo sua participação ao voto - ou seja, a uma forma passiva e extremamente limitada. A nova concepção de democracia, portanto, faz o oposto do verdadeiro valor democrático. Ela cria a ilusão de participação popular, mas mantém o povo fora dos espaços de poder, por meio da representação política. Ellen Wood nos chama a atenção para a astúcia americana ao fazer isso:

Já nos acostumamos tanto à fórmula "democracia representativa" que tendemos a esquecer a novidade da ideia americana. Pelo menos em sua forma federalista, ela significou que algo até então percebido como a antítese do autogoverno democrático passa a ser não apenas compatível com a democracia, mas também um de seus 
componentes: não o exercício do poder político, mas renúncia a esse poder, sua transferência a outras, sua alienação [WOOD, 2003, p. 187].

Ao mesmo tempo em que a cidadania passou a ser mais inclusiva, ela também foi esvaziada de seu "conteúdo social". Os direitos políticos foram estendidos e universalizados, mas se reduziram a uma participação passiva nas esferas de poder. Essa nova formatação do conceito de democracia resultou na passagem "do exercício ativo do poder popular para o gozo passivo das salvaguardas e dos direitos constitucionais e processuais, e do poder coletivo das classes subordinadas para a privacidade e o isolamento do cidadão individual" [WOOD, 2003, p. 196]. Ou seja: cada vez mais, a democracia se identifica com o liberalismo. Atualmente, não consideramos mais a democracia como o "governo do povo", mas sim como uma forma de garantir liberdades civis e individuais, as quais se relacionam cada vez mais com uma esfera privada, e não coletiva e política.

A democracia burguesa, portanto, possui limites inerentes à sua própria constituição. Ela não surge como uma forma de garantir o poder popular à política, mas sim como um meio de gerar ilusão de participação. Em um mundo que possui "democracia" como valor, a democracia burguesa é a solução para manter o povo satisfeito, com a sensação de que possui acesso ao poder político, ainda que sua participação se restrinja ao voto em representantes a cada quatro anos. A democracia burguesa não apenas afasta a população dos espaços de poder, como atomiza esses cidadãos: não há bem público em uma sociedade atomizada, não há nenhuma direção ou alternativa a se seguir, e a política passa a ser reduzida a um conjunto de liberdades civis e individuais. Ora, a política, na democracia burguesa, é uma mera garantidora de direitos como os direitos à liberdade de expressão, à reunião, à privacidade, à pluralidade - dentre outros valores liberais -, e mesmo nisso ela falha.

A representação - ou a democracia burguesa ou representativa - é, pois, um simulacro da democracia: ela reduz a ação política à mera passividade, paralisando e atomizando os cidadãos.

\section{Considerações finais}

Ao longo de nosso trabalho, procuramos mostrar que a democracia representativa não apenas se afasta da democracia ateniense, como perde grande parte de seu conteúdo democrático. No sistema representativo, os cidadãos ficam sujeitos à mera passividade na participação política: o único instrumento institucional para a ação é o voto em representantes que não possuem nenhuma obrigação legal de cumprirem de fato o desejo de seus eleitores. Ou seja, a participação na democracia representativa se reduz ao que Hanna Pitkin chama de autorização: os representados autorizam uma elite a deliberar, sem possuírem nenhuma garantia de respaldo.

Na última seção de nosso texto, vimos que Ellen Wood vai além: ela não apenas afirma que a democracia burguesa é uma democracia que impossibilita a ação política, como mostra que a escolha de nomear a representação como democracia foi um modo de criar uma satisfação ilusória no povo: quando a democracia se torna um valor, não é mais possível negá-la e a solução para isso é estabelecer um novo sistema, denominando-o de democracia.

Mais do que isso, concluímos que a democracia hoje se confunde com a garantia de liberdades civis e direitos individuais que correspondem, principalmente, à vida social e privada, mas não possui um caráter de governo do povo, o que esvazia a palavra de seu conteúdo propriamente político. Enquanto identificamos a democracia com a representação, nossas perspectivas ficam extremamente limitadas - não conseguimos vislumbrar nenhum modelo político que não passe pelas eleições, o que representa uma enorme dificuldade por dois principais motivos: o primeiro deles é que as eleições não são democráticas, uma vez que, com exceção de uma minoria - que por ser minoria é incapaz de travar disputas dentro do Congresso -, somente são eleitos aqueles que atendem aos interesses da classe dominante, já que o processo 
eleitoral demanda dinheiro. O segundo ponto é que, enquanto percebermos a democracia como necessariamente representativa, permaneceremos incapazes de apontar uma alternativa que amplie a participação política popular, e sequer conseguiremos pensar em formas de aproximação do povo com a esfera política - coletiva e social. 


\section{Referências}

ALMEIDA, Silvio Luiz de. Satre: Direito e Política. São Paulo: Boitempo Editorial, 2016.

ANDERSON, Perry. Linhagens do Estado Absolutista. Tradução de Suely Bastos. 3. ed. São Paulo: Editora Brasiliense, 1995. 3. ed.

ARISTOTLE. The Politics. Oxford: Oxford Press, 2009.

CHOMSKY, Noam. Midia. São Paulo: Martins Fontes, 2014. Versão Eletrônica.

HAMILTON, A., MADISON, J., JAY, J. The Federalist: with letters of "Brutus". Cambridge: Cambridge University Press, 2003.

MANIN, Bernard. The Principles of representative government. Cambridge: Cambridge University Press, 1997.

PITKIN, Hanna Fenichel. The Concept of Representation. Berkeley: University of California Press, 1972.

ROUSSEAU, Do contrato social. Tradução de Lourdes Santos Machado. 4. ed. São Paulo: Nova Cultural, 1987.

SARTRE, Jean-Paul. Eléctions, pièges à cons, In. Situations X, Paris : Gallimard, 1976.

SIEYÈS, Emmanuel Joseph. Political Writings: Including the debate between Sieyès and Tom Paine in 1791. Indianapolis: Hackett Publishing Company Inc., 2003.

SIEYÈS, Emmanuel Joseph. Qu'est-ce que le Tiers état ? Paris : Éditions du Boucher, 2002.

URBINATI, Nadia. Democracy disfigured: opinion, truth, and the people. Cambridge: Harvard University Press, 2014.

URBINATI, Nadia. Representative Democracy: Principles and Genealogy. Chicago: The University of Chicago Press, 2006.

WOOD, Ellen. Democracia contra capitalismo. São Paulo: Boitempo, 2003.

Autor(a) para correspondência / Corresponding author: Tamíris Moreira Simão. tamiris.msimao@gmail.com 